\title{
Designing an online video based platform for teacher learning in Singapore
}

\author{
Hyo-Jeong So, Hans Lossman, Wei-Ying Lim \\ Nanyang Technological University
}

\section{Michael J. Jacobson}

The University of Sydney

\begin{abstract}
In this paper, we describe our path for designing an online community of practice for teachers in Singapore, from identifying the current status of professional development to designing an online platform where teachers can share vivid images of their teaching practices with other teachers. To identify current practices in professional development, we conducted a large scale online survey with 1605 teachers. The quantitative data collected from this survey gave us a macro-level overview of the current status of teacher professional development in Singapore schools. Next, for a more in depth understanding of teachers' views on professional development experiences and gathering of ideas for designing an online video based environment, we conducted participatory design workshops with 11 teachers in two schools. The purpose of these workshops was to engage end users, who are teachers in Singapore, from an early stage of the design process so that their needs and ideas could be reflected in the final design. Finally, we turned the ideas gathered from the participatory workshops into a concrete design of an online environment for a teacher community. In the design process for this environment, particular attention was given to Web 2.0 technology solutions, which emphasise participation from community members as a key element. In conclusion, we discuss issues and challenges faced in this process, and implications for future research into online professional development actvities.
\end{abstract}

\section{Introduction}

Since the work on situated learning by Wenger and Lave, the peripheral participation of individuals to a community of practice (CoP) has been emphasised in many professional fields, including teacher education (Lave \& Wenger, 1991; Wenger, 1998). What is emphasised in the CoP framework is not only practices of practitioners in that field, but also identities, artifacts, and tacit knowledge shared among community members. One strategy that is deemed promising for teacher learning is professional development through the fostering of CoPs, which provides a valuable platform for teachers to connect and interact among themselves, to share and support each other on the specific problems, experiences and lessons learned, and to do so at their own time and pace. Problem solving in this context of CoPs is not an academic exercise, but a means towards finding a practical and informed resolution in matters that have implications to society and others. Communities of practice thus reflect a constructivist, in situ social approach to learning that is rather different from the current practices adopted in traditional professional development and consistent with professional learning in other professions (Brown \& Duguid, 2000). 
In Singapore, we attempted to explore how to foster such CoPs for teachers where they can share their knowledge, ideas, and artifacts with others in the same field, in a technology mediated environment. This paper reports our path towards designing a $\mathrm{CoP}$ for teachers in Singapore, from identifying the current status of professional development to designing an online platform where teachers can share vivid images of their teaching practices with other teachers. To identify the current practices of professional development, we conducted a large scale online survey in which 1605 teachers at primary, secondary and junior college levels participated. The quantitative data collected from this survey gave us a macro-level overview of the current status of teacher professional development conducted in Singapore schools.

Next, for more in depth understanding of teachers' views on professional development experiences and gathering of ideas for designing an online video based environment, we conducted two participatory design workshops with 11 teachers in two schools. The purpose of the participatory design workshops was to engage end users, who are teachers in Singapore, from an early stage of the design process so that their needs and ideas could be reflected in the final design. Finally, we turned the ideas gathered from the participatory workshops into a concrete design of an online environment for a teacher community. In the design process of this online environment, a particular attention was given to Web 2.0 technology solutions, which emphasise participation from community members as a key element. In conclusion, we discuss issues and challenges faced in this process, and implications for future research into online professional development activities.

\section{Theoretical background}

\section{What is effective teacher professional development?}

Traditional teacher professional development programs have been criticised for being ineffective because they are often organised as fragmented and intellectually superficial workshops or seminars (Borko, 2004). These are typically in the form of prepackaged training courses conducted by external agencies outside school curriculum time. Such training seemed to assume that first, knowledge exists in distinct units which can be transferred from trainers to teachers. Second, that this knowledge if "received" can be applied to classroom situations when required. Such assumptions have resulted in connections of new knowledge to classroom situations being left to individual teachers who more often than not, are either consumed by their routine leaving them little time to reflect and solve problems, or are overwhelmed by the difficulties encountered, causing them to return to their old practices.

Drawing from the CoP and the situated learning literature, it is argued that teacher professional development can be more effective when it provides authentic training set in real life practice. Such practice based learning, whereby one learns through participation in context, is probably more effective than an abstract, transmissional type of training received from external parties. Through enculturation, teachers not only learn the knowledge and skills inherent in the practice but more importantly, identify with the shared meaning and purpose in being an educator.

Among the many benefits for teachers in communities of practices (see Putnam \& Borko, 2000; Schlager \& Fusco, 2003), we highlight those we regard as most pertinent in educational contexts. Education CoPs, as suggested by Schlager and Fusco (2003), 
are distinguishable from other types of communities. Education CoPs are based on the mutual engagement by members of various stakeholder groups in the collective enterprise or practice of educating students. In this collective enterprise, instead of learning from external experts, teachers learn from one another, constituting an interactional shift away from external experts to an approach that relies heavily on the social networks within the teachers' own sphere of contacts. It can be argued that learning under such circumstances is highly relevant, directly addressing personal experience. In addition, such practice oriented ways of learning are often just in time, based on real time needs, enabling a tighter coherence and integration of pedagogies to situation, linking theory to practice.

\section{Video technology as a vehicle for teacher CoPs}

Several researchers in teacher education have explored how to design CoPs in online environments, and video technology has been suggested as an effective medium that teachers can use to share vivid images of teaching and learning practices in classrooms (Fishman \& Davis, 2006). The use of videos for teacher learning has been discussed since the 1960s (Brophy, 2004). The arrival of the VHS, compact disc (CD), and digital video disc (DVD) as flexible delivery formats renewed interest in the use of video technology to prepare student teachers and to provide opportunities for teacher professional development. Recently, the advance of digitalised information technology has provided new possibilities to segment and present educational materials in flexible and accessible ways that were not possible previously (Jonassen, Wang, Strobel \& Cernusca, 2003). Today, the further development of streaming media technology together with an increase in the number of people having access to high bandwidth has made the Internet a suitable and popular channel for the distribution of video based materials for learning purposes.

There are several online, video based platforms for teacher professional development (Fishman \& Davis, 2006). To examine existing online video case libraries, we selected three different web sites that use video cases to support teacher professional development in online environments. These are:

- Inquiry Learning Forum (ILF) [http:/ /ilf.crlt.indiana.edu/]

- Knowledge Networks on the Web (KNOW) [http:// know.umich.edu/], and

- Arizona Best Practices [http://pt3.ed.asu.edu/bestpractices/] and [http:/ / azk12.nau.edu/bestpractices/videocases/]

We selected these three websites for review due to their particular focus on in-service teacher learning, sharing of pedagogical practices, and availability of supporting literature. Hence, online, video based platforms focusing on pre-service teacher learning or commercial websites without supporting literature were excluded from this review. It should be noted that the aim of this review was not to make comprehensive and evaluative statements, but rather to identify what could be learned from existing ones by looking at their strengths and weaknesses whilst gathering ideas for our prototype design.

First, the Inquiry Learning Forum (ILF) is designed around an idea of specific pedagogical practices to cater for the group of teachers interested in inquiry based pedagogy. The ILF has several components, including a library of lesson plans and web resources, a collection of inquiry based professional development labs, a collaboratory with a variety of public and private asynchronous discussion forums, 
and a collection of video based classrooms, which is the heart of the ILF. The video cases are intended to capture "teaching in a variety of settings from teachers who have a variety of strengths and weaknesses... to foster a greater amount and quality of discussion both on-line and in-situ" (Barab, MaKinster, Moore \& Cunningham, 2001, p. 79). Since the ILF was originally designed to support maths and science teachers, the vast majority of the video vignettes are from maths and science lessons at the secondary level. Each video classroom shows a lesson which has been edited and broken into several 3-10 minute video clips. Each classroom also has several additional resources supplied by the participating teacher including a lesson overview, a detailed lesson plan, the teacher's reflections for each video clip, examples of student work, relation to relevant state and national standards, and links to accompanying resources.

Second, the underlying idea for the Knowledge Networks on the Web (KNOW) is to integrate videos with existing curricular for middle school science education. Similar to the ILF, the pedagogical approach is mainly about inquiry based learning. The site delivers a package solution such as educative curriculum, readings for students, and streaming videos. Besides the core content, there are a number of external links to different software that can be used for educational purposes, and downloadable software for desktop PCs and handheld devices. The main benefit of this package approach might spell relevance because connecting the video cases to a specific curriculum can make impacts on the teacher's actual practices (Fishman, 2004). The KNOW site contains two types of video cases: images of practice and 'how to' videos. While the images of practice videos shows the embodiment of inquiry oriented pedagogy in classrooms, 'how to' videos feature certain technology or tools tied to pedagogical content knowledge (Fishman, 2004). The video cases have a double function in such a way that it allows students to join a class or watch a demonstration while teachers may benefit from observing educational practices and pedagogy used in the video. There is also an online forum for discussion among members.

Finally, Arizona Best Practices is developed to showcase exemplary teaching and methodology for K-12 teachers. The Arizona Best Practices website differs from other video case libraries because it is a pure resource site and does not aim to promote certain pedagogical practices, or to support any specific type of online communities. The Best Practices in this website is "not meant to imply that the teachers included in the database are the best. Rather, the practice of continually questioning and improving their teaching through evaluation and reflection is a component of best teaching practices" (Kurz, Llama \& Savenye, 2005, p. 69). Each video case contains several subcategories: lesson information, peer interview, actual lesson (introduction, presentation, activities, and closure), post interview, follow up, and comment. Such link categories provide some ideas on how to segment videos of a single lesson at fine grained levels, an issue that is considered to be important in the development of useful video cases (Stephens \& Leavell, 1999).

Table 1 summarises the comparison of these three websites in terms of focus, community support, video and content, and limitations. The comparison of the video case libraries shows that each one of them has its own specific strengths and weaknesses. Three important issues that emerged in this review were (a) lack of online community support, (b) centralised content creation and sharing, and (c) culturally and contextually relevant content. For instance, while the KNOW website contains an online discussion forum for members, browsing through the sparse entries in the forum shows the dilemma of fading online communities where there is a lack of 
engagement and contributions from community members. A centralised system for creating and sharing content is another important issue. The video cases in all three websites seem centrally created and managed by the research teams, which makes flexible sharing and updating by community members rather difficult. Lastly, it became clear that some existing video cases may not be so relevant to Singapore teachers, due to the differences in school curricula and classroom contexts, which imply the importance of locally produced content instead of using content produced in other cultural and educational contexts. This motivated us to design an online, video based platform relevant for Singapore teachers to create and share video content in a flexible way. The remaining part of the paper explains our design process in detail.

Table 1: Comparisons of three example sites

\begin{tabular}{|c|c|c|c|}
\hline & $\begin{array}{l}\text { Inquiry Learning } \\
\text { Forum (ILF) }\end{array}$ & $\begin{array}{l}\text { Knowledge Networks } \\
\text { on the Web (KNOW) }\end{array}$ & $\begin{array}{c}\text { Arizona } \\
\text { Best Practices }\end{array}$ \\
\hline Focus & $\begin{array}{l}\text { Community building for } \\
\text { sharing methods and } \\
\text { practices of inquiry based } \\
\text { learning }\end{array}$ & $\begin{array}{l}\text { Coherence and integration } \\
\text { between curriculum } \\
\text { materials and videos to } \\
\text { support inquiry oriented } \\
\text { science learning }\end{array}$ & $\begin{array}{l}\text { Videos of good } \\
\text { pedagogical practice and } \\
\text { methodological } \\
\text { approaches }\end{array}$ \\
\hline $\begin{array}{l}\text { Community } \\
\text { support }\end{array}$ & $\begin{array}{l}\text { Forum; Member's personal } \\
\text { page; Uploading and } \\
\text { sharing of files and lessons }\end{array}$ & Forum for discussion & Not available \\
\hline $\begin{array}{l}\text { Video and } \\
\text { content }\end{array}$ & $\begin{array}{l}\text { Videos contributed by } \\
\text { members (after being } \\
\text { reviewed by the ILF staff); } \\
\text { Experimental approach. } \\
\text { Informal and less } \\
\text { structured (as compared to } \\
\text { the KNOW and Best } \\
\text { Practices) }\end{array}$ & $\begin{array}{l}\text { Determined by curriculum } \\
\text { content; Functional } \\
\text { approach }\end{array}$ & $\begin{array}{l}\text { Created by a recording } \\
\text { team; Well-structured and } \\
\text { formalised procedures for } \\
\text { pre and post interviews }\end{array}$ \\
\hline Limitations & $\begin{array}{l}\text { Minor technical } \\
\text { shortcomings like small } \\
\text { windows and video quality }\end{array}$ & $\begin{array}{l}\text { The strength of this site is } \\
\text { also its weakness. The } \\
\text { content is locked into a } \\
\text { certain context of } \\
\text { curriculum that may limit } \\
\text { the range of applications. }\end{array}$ & $\begin{array}{l}\text { Centralised content } \\
\text { creation; No support for } \\
\text { community }\end{array}$ \\
\hline
\end{tabular}

\section{The present research}

In this research, we view teacher learning as a developmental path, consisting of three major stages, namely pre-service training, induction into teaching, and continuing education (Feiman-Nemser, 2001). A critical question in teacher education research is how to support this developmental path after pre-service training so that teachers in school can continuously harness their knowledge base and skills, and engage in examining their understanding and practices of teaching and learning with social supports. Thus, an overarching question in the present research is "how can we support teacher learning with a medium of video based technology?"

We started the research study by examining the current status of teacher professional learning after pre-service training (discussed in the following section): do teachers have enough opportunities for professional development?; what topics are discussed and taught in professional development programs? Then, we conducted participatory design workshops with 11 teachers in two schools to find out: what do teachers 
perceive about their professional development experiences; what do they expect to experience in online video based platforms designed for a teacher community? Finally, we synthesised out data and ideas to design a Web 2.0 integrated video case library for a teacher learning community.

\section{Current status of professional development in Singapore}

To collect baseline data about Singapore teachers' in perceptions of their experiences with professional development, we conducted an online survey, comprising items related to overall school culture (e.g., whether schools encourage collaboration among teachers, provide opportunities for teacher professional development) and, more specifically, the content of the professional development (e.g., topics covered in programs). The items are taken from the national survey designed by Becker and Riel (1999). There were 1886 teachers from 51 schools $(14.2 \%$ of the total number of schools in Singapore) who participated in this survey. Among them, 1605 completed all sections of their surveys, thereby giving a response rate of approximately $85 \%$. In terms of school settings, the majority of the respondents were from primary schools ( $\mathrm{n}$ $=1247,66.3 \%$ of the sample. There were 1459 female and 422 male teachers $(1$ missing entry) who participated in the survey. Of the sample, $32.3 \%$ were in the service for $0-3$ years, $37.9 \%$ for $4-10$ years, $14.6 \%$ for $11-20$ years, and $15.2 \%$ for more than 20 years.

Table 2: Descriptive statistics of survey data

\begin{tabular}{|c|c|c|c|c|}
\hline \multirow{2}{*}{\begin{tabular}{|l|}
\multicolumn{1}{|c|}{ Category } \\
School \\
culture
\end{tabular}} & \multicolumn{2}{|r|}{ Item } & \multirow{2}{*}{$\begin{array}{c}\text { Mean } \\
4.53\end{array}$} & \multirow{2}{*}{$\begin{array}{c}\mathrm{SD} \\
1.00\end{array}$} \\
\hline & 1 & $\begin{array}{l}\text { Teachers play an important role in defining staff development } \\
\text { activities. }\end{array}$ & & \\
\hline & 2 & Other teachers encourage me to try out new ideas. & 4.40 & .96 \\
\hline & 3 & $\begin{array}{l}\text { Major staff development activities are followed by support to } \\
\text { help teachers implement new practices. }\end{array}$ & 4.32 & 1.03 \\
\hline & 4 & $\begin{array}{l}\text { New ideas presented at professional development workshops } \\
\text { are discussed afterwards by teachers in this school. }\end{array}$ & 4.28 & .98 \\
\hline \multirow{12}{*}{$\begin{array}{l}\text { Topics in } \\
\text { professional } \\
\text { development }\end{array}$} & 5 & Content to teach your students. & 4.39 & 1.17 \\
\hline & 6 & $\begin{array}{l}\text { New knowledge about your subject-matter (for your own } \\
\text { education). }\end{array}$ & 4.30 & 1.16 \\
\hline & 7 & $\begin{array}{l}\text { Improving how well students work in groups or peer } \\
\text { discussions. }\end{array}$ & 4.20 & 1.14 \\
\hline & 8 & Improving students' critical thinking or problem solving. & 4.15 & 1.16 \\
\hline & 9 & $\begin{array}{l}\text { Integrating computers into instructional activities in your subject } \\
\text { area. }\end{array}$ & 4.11 & 1.13 \\
\hline & 10 & The mechanics of using computer technology and software. & 3.96 & 1.19 \\
\hline & 11 & $\begin{array}{l}\text { Connecting content with student interests or with students' prior } \\
\text { knowledge. }\end{array}$ & 3.94 & 1.22 \\
\hline & 12 & How to use the Internet or other online activities. & 3.90 & 1.22 \\
\hline & 13 & $\begin{array}{l}\text { Improving students' meta-cognition (their ability to monitor how } \\
\text { well they are learning something). }\end{array}$ & 3.88 & 1.23 \\
\hline & 14 & $\begin{array}{l}\text { Improving students' abilities to write or to review other students' } \\
\text { writing. }\end{array}$ & 3.73 & 1.29 \\
\hline & 15 & Connecting skills instruction with real world applications. & 3.67 & 1.28 \\
\hline & 16 & How to enable students to create multimedia presentations. & 3.42 & 1.36 \\
\hline
\end{tabular}

Notes: Scale range for the school culture category is 1 = "Strongly disagree", 2 = "Moderately disagree", 3 = "Slightly disagree", 4 = "Slightly agree", 5 = "Moderately agree", 6 = "Strongly agree". Scale range for the topics in professional development is $1=$ "Topic not discussed at all", 2 ="Topic hinted at, but not mentioned", 3 ="Topic mentioned in passing", 4="Topic mentioned briefly", 5="Topic mentioned substantially", 6="Central topic". 
On the whole, the survey data on school culture show that teachers had favorable perceptions of whether their school encourages collaboration and teacher initiatives in staff development (Table 1). Comparison among the means related to topics in professional development reveal that content to teach students $(\mathrm{M}=4.39, \mathrm{SD}=1.17)$ and new knowledge about subject matter $(\mathrm{M}=4.30, \mathrm{SD}=1.16)$ were topics that were mentioned fairly substantially. However, mean scores of topics related to technology components such computer software, online activities, and multimedia presentation, are below 4.0, indicating that these topics are often mentioned in passing. Data also show that topics related to meta-cognition and constructivist pedagogy are not discussed substantially in professional development programs.

Becker and Riel (1999) argue that whether the type of school culture is collaborative (e.g., one that encourages shared learning, collaboration, innovation) or bureaucratic (e.g., one that is hierarchical and emphasises structures and systems), has an impact on teachers' pedagogical practices. The survey data imply that teachers in Singapore perceived their school culture as being a collaborative one, which is a positive sign for fostering a collaborative teacher community. Overall, the survey finding led us to question where teachers could expand their knowledge base by learning about new pedagogies and technology related practices, and whether technology could play a role in building a collaborative environment for teachers to share and expand their knowledge. To further pursue this question, we organised participatory design workshops with teachers, as described in the next section.

\section{Methodology}

\section{Participatory design for engaging end users in the design process}

With basic understanding of the current practices and perceptions of teacher professional development from the survey findings, we moved to the next phase, designing a video case library as an online platform for a teacher learning community. Instead of the traditional design process driven by researchers or designers, we adopted a participatory design (PD) approach to engage end users, who are teachers in Singapore, in this design process. Participatory design has its origin in the Swedish union movement. It was initially brought forward to involve end users in the design of the tools that they were about to use. The ideological foundation for this movement was to make the design process more democratic (Bjerknes, Ehn \& Kyng, 1987). By allowing stakeholders to get involved at an early stage of the design process, they are empowered to influence the final product with suggestions and ideas. Recently, the participatory design community has been revitalised by the emergence of the Internet. In the wake of its expansion, there has been a need for the development of new digital artifacts such as technology supported learning environments, databases, websites, forums, and online communities. To be able to create such digital artifacts with high usability, there has been a demand for a methodological approach that involves end users in an early stage of development, such as participatory design used in this study (Luke et al., 2004).

The theoretical rationale for constructing participatory design workshops in this project was to create what is known as a third space where stakeholders and experts from different domains can meet and discuss issues of common interests:

In PD, workshops are usually held to help diverse parties communicate and commit to shared goals, strategies, and outcomes (e.g., analyses, designs, and evaluations, as well 
as workplace-change objectives). Workshops are often held at sites that are in a sense neutral... More important, workshops usually introduce novel procedures that are not part of conventional working practices... Workshops are thus a kind of hybrid or third space, in which diverse parties communicate in a mutuality of unfamiliarity, and must create shared knowledge and even the procedures for developing those shared knowledge (Muller, 2003, p. 1056).

A common problem in the design of artifacts, whether they are physical or digital, is the lack of a shared language among experts from different domains. Hence, designers might use a terminology related to their work practices, while people developing artifacts use another terminology. This dilemma concerns what is known as different language games, a concept first introduced by Ludwig Wittgenstein (1953). Language games reflect an idea of human language as a living activity where participants create meanings. The concept of language games has been transferred into different academic contexts, and has been pointed out as an important factor in the field of participatory design as well (Crabtree, 2000).

To overcome the dilemma of different language games, it is of importance to bring the domain specific knowledge of all parties into the process of design. Following the idea of language as a living activity, our workshop abandoned the traditional format with experts and novices. Rather, we allowed participants to play roles as both experts and learners in the design process. Everyone in participatory design is supposed to bring his or her domain specific knowledge into this neutral third space. When this is done successfully, it creates a common terminology and understanding between designers and future users. This process gives everyone involved crucial insights into the possibilities and restrictions of design as well as awareness of the user experiences, ideas, and provisos. The new knowledge makes up the theoretical and practical foundation for the further development of the artifact. In the case of developing an online video based platform, for us this meant considering participants' experiences of professional development, meaning what they considered to be useful for online teacher communities, video cases, and technological solutions.

\section{Constructing participatory design workshops}

We arranged participatory design workshops with two schools (one primary and one secondary) in Singapore to gather information for the design of our video case library. As shown in Table 3, we specifically requested a mix of participant characteristics such as their ages, genders, and teaching experiences. The reason for this was to ensure that different ideas would be brought forward, and that all stakeholders would be represented in the design process.

The purpose of the participatory design workshops is to "avoid the overly abstract representations of traditional design approaches... and to more easily experiment with various design possibility in cost-effective ways" (Kensing \& Blomberg, 1998, p. 179). Thus, various techniques such as scenarios, mock ups, and collaborative prototyping were used to encourage active participation and creative ideas. The workshops were carried out for about one and a half hours, and were structured according to the participatory design phases described in Table 4 . In each phase, we collected various types of data such as audio recording, field notes, and artifacts created by participants (e.g., post-it notes, sketches, pictures). 
Table 3: Participatory design workshop participants

\begin{tabular}{|c|c|c|c|c|}
\hline & Participant & Gender & Subject & $\begin{array}{l}\text { Teaching } \\
\text { experience }\end{array}$ \\
\hline \multirow{4}{*}{$\begin{array}{c}\text { Workshop } \\
1\end{array}$} & 1 & Female & Chemistry & 14 years \\
\hline & 2 & Female & Math, physics & 2 years \\
\hline & 3 & Male & Math & 1.5 years \\
\hline & 4 & Male & Math, CPA & 8 months \\
\hline \multirow{7}{*}{$\begin{array}{c}\text { Workshop } \\
2\end{array}$} & 1 & Female & Music & \\
\hline & 2 & Male & Chinese language & 1 year \\
\hline & 3 & Male & Physical education & 5 years \\
\hline & 4 & Female & English, math, science & 2 years \\
\hline & 5 & Male & Science & 1 year \\
\hline & 6 & Female & English, math & 4 years \\
\hline & 7 & Male & Science & 4 years \\
\hline
\end{tabular}

Table 4: Participatory workshop structure

\begin{tabular}{|c|c|c|c|}
\hline & Phase of workshop (time) & Purpose & Type of data \\
\hline 1 & $\begin{array}{l}\text { Participants introduce } \\
\text { themselves (10 mins). }\end{array}$ & $\begin{array}{l}\text { To create a common ground for the } \\
\text { workshop and find out about the } \\
\text { participants' background. }\end{array}$ & $\begin{array}{l}\text { Voice recording, } \\
\text { notes, pictures. }\end{array}$ \\
\hline 2 & $\begin{array}{l}\text { Explain purpose of } \\
\text { workshop (10 mins). }\end{array}$ & $\begin{array}{l}\text { To inform the participants of what we } \\
\text { wish to achieve with the workshop (i.e., } \\
\text { gather creative ideas, considerations, and } \\
\text { opinions to inform the design of a video } \\
\text { case library). }\end{array}$ & $\begin{array}{l}\text { Voice recording, } \\
\text { notes. }\end{array}$ \\
\hline 3 & Present scenarios (10 mins). & $\begin{array}{l}\text { Individual task: To create a creative } \\
\text { framework for the participants to } \\
\text { contribute with ideas. }\end{array}$ & $\begin{array}{l}\text { First hand notes } \\
\text { and opinions from } \\
\text { the participants. }\end{array}$ \\
\hline 4 & $\begin{array}{l}\text { Discussion of issues for using } \\
\text { videos in professional } \\
\text { development ( } 10 \text { mins). }\end{array}$ & $\begin{array}{l}\text { Discuss common issues concerning the } \\
\text { use of videos in teacher professional } \\
\text { development (e.g., indexing of videos, } \\
\text { segmenting, use of complementary } \\
\text { material, etc). }\end{array}$ & $\begin{array}{l}\text { Voice recording, } \\
\text { notes. }\end{array}$ \\
\hline 5 & $\begin{array}{l}\text { The participants are split into } \\
\text { two groups to create a paper } \\
\text { mock up of a video case } \\
\text { library ( } 20 \text { mins). }\end{array}$ & $\begin{array}{l}\text { Collaborative task: To allow the } \\
\text { participants to visualise creative ideas } \\
\text { they might want to share and discuss } \\
\text { with their peers. }\end{array}$ & $\begin{array}{l}\text { Sketches, notes, } \\
\text { pictures. }\end{array}$ \\
\hline 6 & $\begin{array}{l}\text { Presentation and discussion } \\
\text { of paper mock ups (20 mins). }\end{array}$ & $\begin{array}{l}\text { To share ideas and discuss pros and cons } \\
\text { of the suggested ideas; To see if some } \\
\text { consensus could be reached. }\end{array}$ & $\begin{array}{l}\text { Sketches, notes, } \\
\text { pictures, voice } \\
\text { recording. }\end{array}$ \\
\hline
\end{tabular}

\section{Results}

\section{Findings from participatory design workshops}

The different phases of the workshop provided different kinds of data. Some of the information provided was important in and by itself while other information helped to create a richer understanding of teachers' work practices and perspectives on professional development.

Phases 1 and 2: Introduction and presentation of purpose

The purpose of the first two phases was to create a common ground for the workshop, and to gather participant perspectives on the design of a video case library related to their previous experiences of teacher professional development. In general, 
participants indicated that video cases are seldom used in professional development, and that most of the professional development was arranged through the Ministry of Education in face to face formats. All the teachers, however, showed positive attitudes toward having an online access to video cases. Participants also expressed their willingness to share views and reflections on video cases with other teachers within or beyond their own school settings through asynchronous or synchronous channels.

Field notes taken from the Phases 1 and 2 provided the following information about functions of a video case library that the participants perceived to be important $\left(\mathrm{A}^{*}, \mathrm{~B}^{*}\right.$, $\mathrm{C}^{*}$ indicate features that have been implemented into the prototype. This is described below in the section entitled "Turning ideas into design"):

- Downloadable video cases: Participants commented on the disadvantage of streaming media like small windows, irritating breaks for buffering, and blurred and inferior image quality as compared to standard DVDs. This calls for a function that allows the viewer to download a high quality version of the video cases for viewing on their personal computer. $\left(\mathrm{A}^{*}\right)$

- Grain size: There were some comments and agreements that videos should be kept short and edited to capture the essentials of the classroom lessons. This would also resolve problems with slow downloading and buffering time.

- Search: Teachers wanted to have an easy to use search function $\left(B^{*}\right)$ where they could search video cases by subject areas, grades, or topics.

- Access issue: Participants mentioned the need to have limited access only to registered users $\left(\mathrm{C}^{*}\right)$ rather than allowing a public access for confidential issues.

- Library inside library: This function would allow users to browse video cases and to create a personal library for future use. $\left(D^{*}\right)$

Phases 3 and 4: Participant contributions based on given scenarios

For this part of the workshop, participants were presented with two scenarios that they could reflect on problems concerning online video cases as a means to provide teacher professional development. The first scenario was presented as follows:

You were told by a colleague that there is a video case library on the Internet for teacher professional development. You visited the webpage, found a title, and pushed the play button. Our questions are; (a) what would make you watch the full video case and feel that the video is a truly useful resource? (b) What would make you turn off the video and leave the website?

The second scenario was about what participants considered to be important for a video case to be interesting and useful. The scenario was formulated as shown below:

Based on your ideas on what makes an interesting video case, we want you to think about the following challenge. Your principal has put you in charge of a recording team that will record a lesson at your school. By reflecting on your own ideas of how to make an interesting video case, what instructions would you give the recording team? Make a simple list.

While the first scenario provided information about positive and negative aspects influencing their use or non-use of video cases, the second scenario provided some ideas on what information teachers want to receive from video cases. Each participant 
was asked to write down their ideas on post-it notes and put them up on a cardboard. Table 5 presents a compilation of the suggestions written down on the post-it notes for the first scenario. Overall, participants' main concerns were about the content and quality of video cases, such as relevance to their teaching areas, short lengths, multimedia components, downloading time, and so on.

Table 5: Summary of scenario 1 findings

\begin{tabular}{|c|c|}
\hline $\begin{array}{c}\text { Question A } \\
\text { (What makes me stay at VCL) }\end{array}$ & $\begin{array}{c}\text { Question B } \\
\text { (What makes me leave VCL) }\end{array}$ \\
\hline Relevant to subject teaching & Irrelevant to subject teaching \\
\hline Interesting and new ideas & Boring content \\
\hline High resolution and clarity of audio & Blurred image \\
\hline Appropriate length (e.g., less than 5 mins) & Lengthy (e.g. above $20 \mathrm{~min}$ ) \\
\hline Short (down)loading time & Slow (down)loading speed \\
\hline Sound effect / music & No visual and sound \\
\hline $\begin{array}{l}\text { Replay function to capture or review } \\
\text { essential points }\end{array}$ & Not user friendly \\
\hline
\end{tabular}

For the second scenario, participants suggested that they would ask the recording team to move a camera or to position multiple cameras in order to capture an overall picture of various activities happening in the classroom. They also indicated that it is critical to interview both teachers and students to know more about their views on a lesson. Some of the questions that participants perceived to be important to ask were:

Questions to pupils

- (Before lesson) what do you know about the topic?

- What do you like the most about the lesson?

- What are three things that you have learned?

Questions to teachers

- How long did it take to prepare the lesson?

- What are the preparations that must be done to conduct this lesson?

- How can you ensure that all pupils have participated actively during the lesson?

- What could be done better in your lesson?

- Do you have any difficulties faced when preparing or conducing the lesson?

Phases 5 and 6: Creation of a paper mock up for a video case library

In the final phases of the workshop, the participants were asked to split into two groups in order to collaboratively create a paper mock up of a video case library. We gathered the suggested features on the whiteboard as shown in Figure 1, and had discussion with participants. Interesting ideas emerged such as top rated videos, 30 second previews, detailed search function, and personalised folders. In summary, the final mock up exercise complemented the initial discussions and the data gathered from the scenarios. Some of the findings from the participatory design workshops were integrated into our prototype design of a video case library.

\section{Turning ideas into design}

Looking for the best design solution, we had to consider a number of factors: (a) how well does the suggested solution fulfill the requirements and ideas of the end user?; (b) what are the overall costs for development and maintenance?; (c) how flexible is the system to create a sustainable community of practices among teachers?; and (d) how reliable and 
secure is the suggested solution? We incorporated design ideas gathered from the participatory workshop into designing an online, video case library. At the same time, we as researchers tried to provide new design solutions to overcome the limitation of existing online, video based platforms, as discussed earlier in this paper.

$\left(E^{*}\right)$ Basic information about the lesson after search.

Ex. Subj. (language, science, maths)/

Level (primary, secondary, JC)/

Difficulty (easy, medium, advanced)
30 sec preview of the video to get a sense of content.
Top rated videos: Videos rated according to the number of views and rating

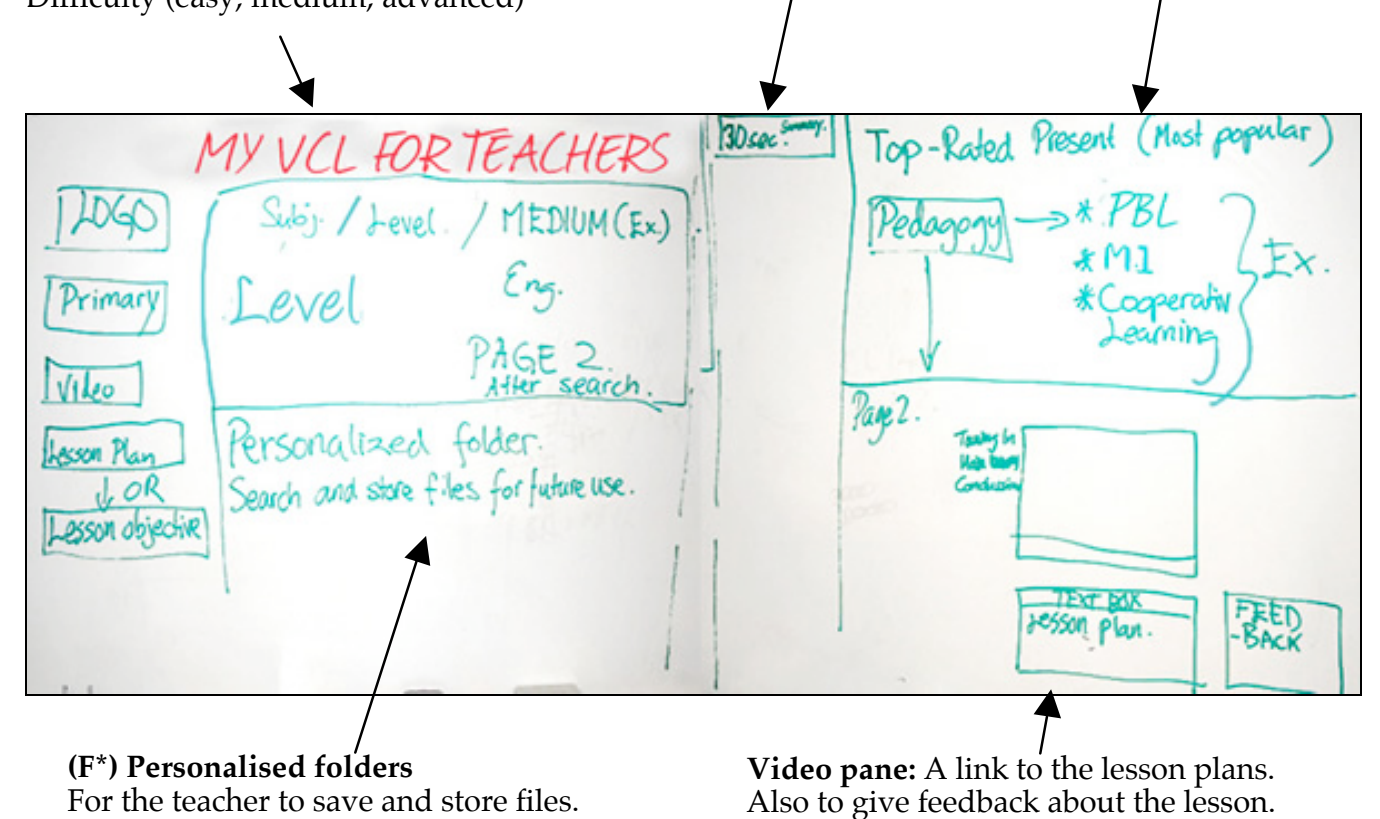

Figure 1: Board notes during a paper mock up session

We observed that many of the existing online communities for teachers are designed based on the idea of traditional supply-push mode of knowledge sharing. There is a need for a demand-pull and participatory learning mode where community members can create and contribute their ideas and knowledge as well as having access to resource rich repositories (Brown \& Adler, 2008). Thus, at this stage of design, our main goal was to explore how the new affordances of emerging technologies, such as Web 2.0 and beyond, could be incorporated into designing an online video base library by making production and sharing processes easy to teachers.

Recently, the emergence of Web 2.0 has radically simplified the process of creating and sharing digital content such as texts, images, and streaming media. People with low to average technological skills can create, model, maintain, or contribute their ideas to online communities and media websites. This Web 2.0 movement is characterised by (a) user created content and information that is shared among members, (b) containing multiple networks based on similar interests and preferences, and (c) an underlying ideology of the power of grass root movements. This movement is known under many different names such as the social web and the semantic web. So far, the big breakthrough for Web 2.0 technology has been through recreational sites like Youtube 
and Last.fm. There has also been a significant growth in the number of personal pages for online social networking where people use services like MySpace, Blogger, and Facebook. In the wake of this trend, there has been a range of complementary services that include RSS readers, tools used to send and receive large files, access to free storage of data, visual design tools, and tagging technology. These add on services can easily be integrated to the Web 2.0 sites.

The recent development of the Web 2.0 technology is interesting for the research community as it has potential to support and facilitate educational communities of practices in online environments. Brown and Adler (2008) argue that the Web 2.0 has created a culture of participatory learning called Learning 2.0, wherein the focus is "learning to be through enculturation into a practice as well as on collateral learning" (p.30, emphasis added). In the area of teacher learning, there has been increasing interest in the role of Web 2.0 technologies for mediating a community of practice for teachers, such as the idea of e-portfolio communities based on the collective generation of sharable artifacts (Albion, 2008; Evans \& Powell, 2007).

The open and emergent nature of Web 2.0 technology may provide some solutions for a common problem of online communities, namely that active participation tends to decrease over time until it sometimes fades away completely (Stuckey \& Barab, 2007). It is important to note that the specific requirement of online learning communities differs in some ways from the unrestricted anarchy of recreational sites. Some guidelines and minimum standards might have to be set on the content as well as on the support to work around technical or infrastructural limitations. Hence, the core challenge for creating online learning communities in the Web 2.0 environment is to provide quality content without dampening the creative enthusiasm of contributing members.

In the prototype design, we considered a number of Web 2.0 tools as shown in Figure 2. First, the Web 2.0 service used for presenting video cases was Blogger. On the start page, we gave a brief introduction to our project and links to complementary software to download, such as RSS readers and software for downloading big files. The Weblog also allows users to invite users who can access the pages. Second, we used the Google Video service for uploading and storing videos. This service allows users to upload unlimited amounts of videos, and to choose whether they want to make the uploaded videos public or private. Once the video is uploaded, there is an embed code created for the video that can be easily copied and pasted into Blogger. Finally, the RSS reader functions as the Library in Library. The RSS guarantees an automatic update of new videos and events in the VCL without users having to visit the VCL to check out for updates. This feature might prevent the decline of interest and help to sustain participation over time. In practice, it would be possible for a school or institution to set up a single account of a RSS reader for all staff to use, as each user can create own folders and subscriptions within the reader.

\section{Discussion and conclusion}

In this paper, we have described a path towards designing an online video case library for Singapore teachers. From the survey and face to face discussion with teachers at the workshop, we found that while teachers perceived their school culture to be collaborative, collaboration across schools is rarely encouraged. Most professional 
$\left(\mathbf{B}^{*}\right)$ Search function for content

(C) Password protected page, limited

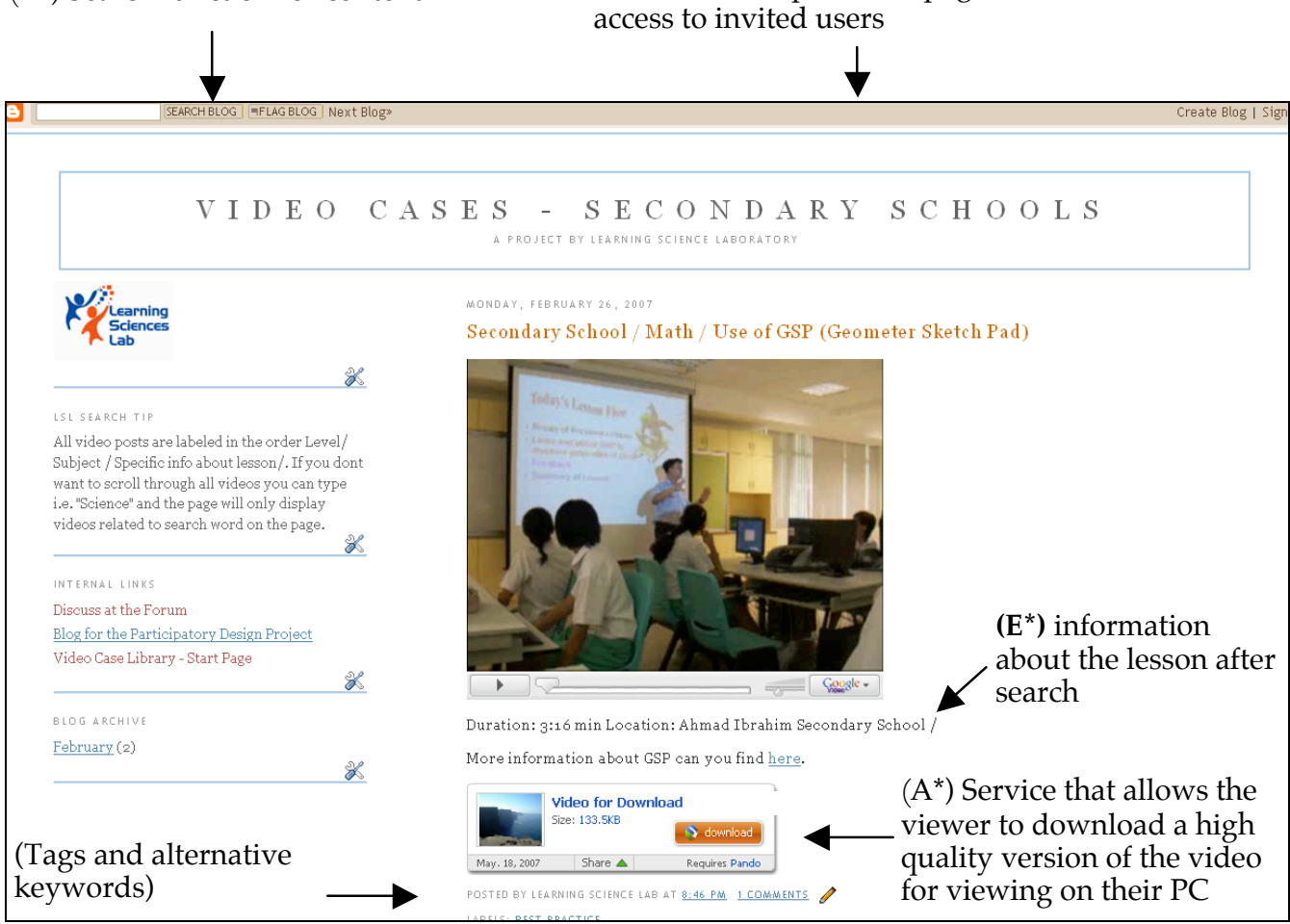

$\left(D^{*}\right)$ Personalised folder for the teacher to save and store video cases and posts

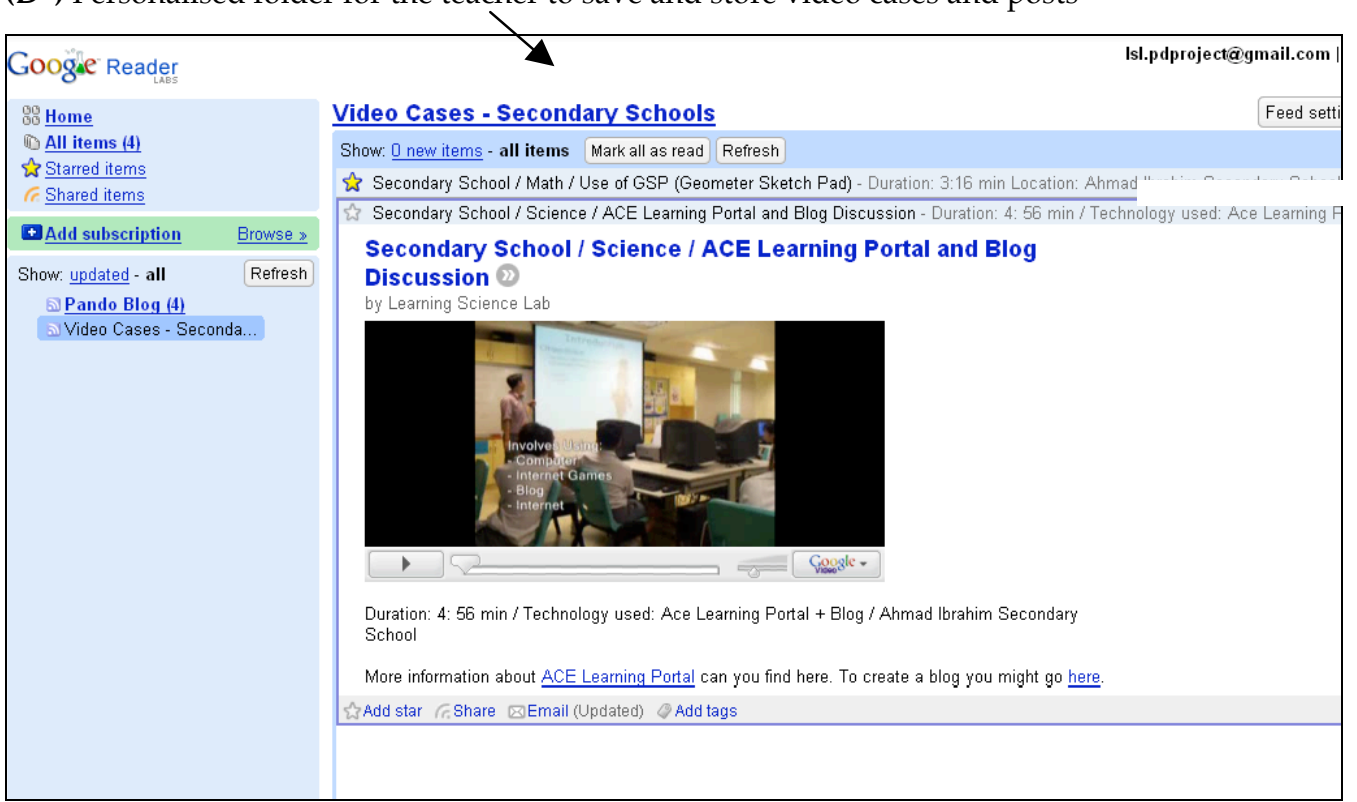

Figure 2: Video case library prototype 
development programs are conducted as a pre-packaged format in a face to face mode. Workshop participants expressed that video technology is seldom used in professional development programs, and that there is a strong need to have access to an online video based community for teachers.

For the past decade, there have been increasing interest in the use of video and web technologies to design online communities for teachers. For instance, Hiebert, Gallmore and Stigler (2002) express a positivistic view about creating an online environment for storing and sharing teachers' professional knowledge: "Imaging large digital libraries linking video examples of teaching, images of students' work, and commentary by teachers and researchers, all integrated around shared topics, and even shared lessons... Teachers faced with teaching particular topics and particular lesson could have immediate access via the Internet to a range of ideas accompanied by vivid examples of alternative practices" (p.8). However, research into the existing online communities for teachers shows that building such communities for teachers is a rather complex process that requires in depth understanding of socio-technical aspects of sustainable communities (Barab et al., 2001; Fishman, 2007). In fact, several attempts to create online communities of teachers have failed or have not lead to sustainable outcomes (Fishman \& Davis, 2006). There might be several reasons for this phenomenon, but one of them would be poor understanding of the social infrastructure underlying successful online communities. For instance, Stuckey and Barab (2007) argue that "good design in socially oriented environments is neither held as a prelude to community nor enough in and of itself to stimulate and support community. Designers, managers and facilitators need to build more than a tolerance for the 'messiness' inherent in social systems, they must learn to leverage it" (p. 439). What appears to be critical in fostering online communities is not to provide rich content resources, but to provide open and emergent structure for participation and sociability.

We employed the participatory design approach with a belief that to design a participatory and sustainable community, it is critical to involve teachers from the early stage of the design process. This participatory model is different from most of the existing video based platforms where a group of researchers select, design, and maintain what goes into video cases. We saw the potential of this bottom up approach since we were able to gather useful ideas from teachers and furthermore, teachers shared their personal views on various issues such as professional development experiences, online communities, and teaching and learning with technology. At the same time, it is important to point out that the idea of participatory design was not sustained after two workshops due to the difficulty of recruiting teachers as committed participants. This may imply a need for a more evolving, open structured process model where teachers perceive themselves as co-designers and continuously engage in design processes in a form of informed participation (Brown \& Duguid, 2000; Fischer \& Giaccardi, 2006).

In terms of the technical aspect of design, we explored various tools and services of Web 2.0 technology to create a prototype. The most successful sites under the Web 2.0 paradigm share the common feature that they partly or completely rely on user created content by providing members with various tools to share content and to build communities around similar interest. In a similar way, our design approach was to create an open and emergent environment where teachers could freely build, share, and contribute their ideas and video cases as well as browsing content for their personal use. With the rapid development and pervasive use of social networking and 
other Web 2.0 services, a new model of teacher communities based on existing social networks may emerge. Future research needs to look into how to utilise these existing social web based networks to build more participatory and sustainable communities for teachers. Furthermore, we believe that in addition to technical solutions, it is important to examine more fundamental issues of community members' intrinsic motivation for participation and sharing, such as what would motivate teachers to create and share video cases? What social support structure should be in place to increase intrinsic motivation and sustained participation? These issues will be examined in our future research.

To conclude, as we reflect on our experience in this design process of employing video technology to facilitate teacher learning and teacher community, it is suggestive that technology alone cannot be the sole reason for the development of teacher community. There requires efforts at a systemic level to create the interdependence amongst teachers that give them imperatives to share. Besides teacher buy in, key stakeholders in the educational system such as school and district leaders have to be supportive of teacher participation in a community. They can range from promoting sharing and allowing teachers to experiment with what they have learnt from the community, to giving incentives to motivate sharing. Such support, we believe, is critical to move teachers from novelty to a more sustained use technology for their learning. We also argue that teachers need to be inculcated with the appropriate epistemologies such that they not only understand the underlying philosophy of how learning occurs in community settings, but that it is in the social interaction with other like minded people that they can improve their personal practice.

\section{Acknowledgment}

This research was funded by a grant from the Learning Sciences Lab at the National Institute of Education, Nanyang Technological University, Singapore.

\section{References}

Albion, P. R. (2008). Web 2.0 in teacher education: Two imperatives for action. Computers in the Schools, 25(3/4), 181-198.

Barab, S., MaKinster, J., G., Moore, J., A. \& Cunningham, J., D. (2001). Designing and building an on-line community: The struggle to support sociability in the Inquiry Learning Forum. Educational Technology Research and Development, 49(4), 71-96.

Becker, H. J. \& Riel, M. M. (1999). Teacher professionalism and the emergence of constructivistcompatible pedagogies. Paper presented at the Annual meeting of the American Educational Research Association, Canada, Montreal.

Bjerknes, G., Ehn, P. \& Kyng, M. (Eds.) (1987). Computers and democracy - A Scandinavian challenge. Aldershot, England.

Borko, H. (2004). Professional development and teacher learning: Mapping the terrain. Educational Researcher, 33(8), 3-15.

Brophy, J. E. (Ed.) (2004). Using video in teacher education (Vol. 10). New York: Elsevier Science.

Brown, J. S. \& Adler, R. P. (2008). Minds on fire: Open education, the long tail, and learning 2.0. EDUCAUSE Review, 43(1), 16-32. http: / / www.educause.edu/EDUCAUSE+Review / EDUCAUSEReviewMagazineVolume43/MindsonFireOpenEducationtheLon/162420 
Brown, J. S. \& Duguid, P. (2000). The social life of information. Boston: MA: Harvard University Business Press.

Crabtree, A. (2000). Talking work: Language games, organisations and computer supported cooperative work. Computer Supported Cooperative Work, 9(2), 215-237. [verified 16 Jul 2009] http: / / www.mrl.nott.ac.uk/ axc/documents/ papers/JCSCW00.pdf

Evans, M. A. \& Powell, A. (2007). Conceptual and practical issues related to the design for and sustainability of communities of practice: The case of e-portfolio use in pre-service teacher training. Technology, Pedagogy and Education, 16(2), 199-214.

Feiman-Nemser, S. (2001). From preparation to practice: Designing a continuum to strengthen and sustain teaching. Teachers College Record, 103(6), 1013-1055.

Fischer, G. \& Giaccardi, E. (2006). Meta-design: A framework for the future of end-user development. In H. Lieberman, F. Paterno \& V. Wulf (Eds.), End user development Empowering people to flexib[y employ advanced information and communication technology (pp. 427-457). Dordrecht, The Netherlands: Kluwer Academic Publisher.

Fishman, B. J. (2004). Linking on-line video and curriculum to leverage community knowledge. In J. E. Brophy (Ed.), Using video in teacher education (Vol. 10, Advances in research on teaching, pp. 201-234). New York: Elsevier Science.

Fishman, B. J. (2007). Fostering community knowledge sharing using ubiquitous records of practice. In R. Goldman, B. B. R. Pea \& S. J. Darry (Eds.), Video research in the learning sciences (pp. 495-506). Mahwah, NJ: Lawrence Erlbaum Associates.

Fishman, B. J. \& Davis, E. (2006). Teacher learning research and the learning sciences. In R. K. Sawyer (Ed.), Cambridge handbook of the learning sciences (pp. 535-550). Cambridge: CUP.

Hiebert, J., Gallmore, R. \& Stigler, J. W. (2002). A knowledge base for the teaching profession: What would it look like and how can we get one? Educational Researcher, 31(5), 3-15.

Jonassen, D. H., Wang, F. K., Strobel, J. \& Cernusca, D. (2003). Application of a case library of technology integration stories for teachers. Journal of Technology and Teacher Education, 11(4), 547-566.

Kensing, F. \& Blomberg, J. (1998). Participatory design: Issues and concerns. Computer Supported Cooperative Work, 7, 167-185.

Kurz, T. L., Llama, G. \& Savenye, W. (2005). Issues and challenges of creating video cases to be used with preservice teachers. TechTrends, 49(4), 67-73.

Lave, J. \& Wenger, E. (1991). Situated learning: Legitimate peripheral participation. Cambridge: CUP.

Luke, R., Clement, A., Terada, R., Bortolussi, D., Booth, C., Brooks, D., et al. (2004). The promise and perils of a participatory approach to developing an open source community learning network. Paper presented at the Participatory Design Conference, Toronto.

Muller, M. J. (2003). Participatory design: The third space in HCI. In J. Jacko \& A. Sears (Eds.), Handbook of HCI (pp. 1051-1068). Mahway NJ: Erlbaum.

Putnam, R. T. \& Borko, H. (2000). What do new views of knowledge and thinking have to say about research on teacher learning? Educational Researcher, 29(1), 4-15.

Schlager, M. S. \& Fusco, J. (2003). Teacher professional development, technology, and communities of practice: Are we putting the cart before the horse? Information Society, 19(3), 203.

Stephens, L. \& Leavell, J. (1999). Producing video-cases that enhance instruction. Journal of Technology and Teacher Education, 7(4), 291-301. 
Stuckey, B. \& Barab, S. (2007). New conceptions of community design. In R. Andrews \& C. Haythornthwaite (Eds.), Handbook of e-learning research (pp. 439-465). London: Sage.

Wenger, E. (1998). Communities of practice: Learning, meaning and identity. Cambridge: CUP.

Wittgenstein, L. (1953). Philosophical investigations. Cambridge: Blackwell Publishing.

Dr Hyo-Jeong So is an assistant professor in the Learning Sciences and Technologies Academic Group and Learning Sciences Lab at the National Institute of Education, Nanyang Technological University in Singapore. Her research interests include computer supported collaborative learning and technology integration. Hans Lossman is a research associate of the Learning Sciences Lab. Ms Wei-Ying Lim is a lecturer in the Learning Sciences and Technologies Academic Group at the National Institute of Education. Michael J. Jacobson is Co-director of the Centre for Research on Computersupported Learning and Cognition and a professor in the Faculty of Education and Social Work, the University of Sydney in Australia.

Dr Hyo-Jeong So, Hans Lossman, Ms Wei-Ying Lim

National Institute of Education Nanyang Technological University, Singapore

Email: hyojeong.so@nie.edu.sg, weiying.lim@nie.edu.sg

Web: http:/ / eduweb.nie.edu.sg/LST/home/default.asp

Professor Michael J. Jacobson, Faculty of Education and Social Work, The University of Sydney, Australia. Email: m.jacobson@edfac.usyd.edu.au

Web: http: / / coco.edfac.usyd.edu.au/Members/mjacobson 